\title{
THE MRS IS YOUR SOCIETY
}

And, As A Participatory Society, It Needs Your Help

As President Elect of the Materials Research Society, it is my pleasure to welcome you to the 1983 Boston meeting. The meeting this year promises to be the best we have ever had. More than 850 papers will be presented, which is an increase of 40 percent over any prior year. This demonstrates growing interest in the Materials Research Society and in the technical areas in which we sponsor symposia. Credit for the success of this year's meeting goes to the Program Committee-Gordon Pike, Bill Appleton and Bernie Kear-and to the individual symposia chairmen for outstanding efforts in assembling a superb technical program.

The Materials Research Society is your society and it is growing at an incredible rate. In the past two years we have arranged to supply our members with an expanding range of membership services including the MRS Bulletin, published six times a year, a membership directory, advantageous prices on volumes in the MRS Proceedings series and a personal subscription to the new journal, Materials Letters. The Society has recently become an Affiliated Society of the American Institute of Physics and members can subscribe to AIPpublished journals at greatly reduced rates. The increased activities of the Society and its growing list of member services have made it necessary to relocate our Headquarters Office and expand its responsibilities. The demand for topical symposia on key topics of materials science can no longer be accommodated in a single yearly meeting. Consequently, beginning next year the Society will sponsor a meeting in the Western United States in the spring of the year. In 1984, this meeting will be held in Albuquerque. Our European members have taken steps to form an affiliated organization in Europe. They organized a highly successful meeting in Strasbourg, France, in May and plan others for 1984 and 1985. A like interest in forming regional affiliates has been expressed in Japan, and in other parts of the world. From all of this you can see that the Materials Research Society is rapidly becoming a truly international society.

The Materials Research Society is your society and we need your help! We have a number of committees-finance, publications, corporate affiliates, education, membership-which help set the agenda directing the future course of the Society, and plan and oversee the development of programs and policies to implement that agenda. These committees offer an opportunity to participate in and help direct the Society's future growth. Their work will be expressed as well in the enhancement of materials science, as the Materials Research Society meets the ever-changing needs of the materials community through its programs and services. Participation in the affairs of the Society also offers a unique opportunity for comradeship with some of the finest men and women scientists, engineers and technologists. Finally, the Materials Research Society is a participatory society and has no established bureaucracy or old-boy network. You can become active and begin to play a role in determining its future simply by expressing your interest and your willingness to work. Please feel free to contact me or any of the other leaders, whether at the meeting or afterward, and we will find a position for you.

During the meeting, a questionnaire will be distributed. The purpose of this is to

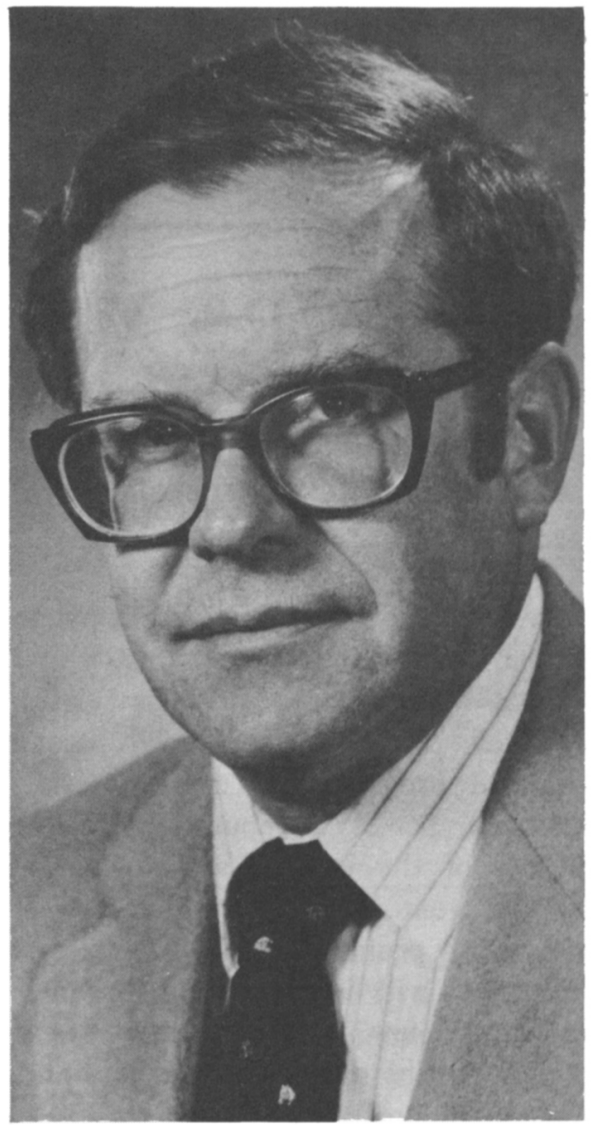

\section{C.W. 'WOODY' WHITE}

- Evaluate the present emphasis in our technical symposia,

- Suggest topical symposia in other areas of materials science, and

- Identify individuals to organize future MRS symposia.

Please take the time to complete this questionnaire and return it to the registration desk. This is your society and it will be responsive to your needs.

I hope you will find this meeting stimulating and rewarding. I hope also that you will take advantage of the opportunities for leadership and service that active participation in the Materials Research Society provides.

\section{Woody White}

President Elect 